\title{
PEMBINAAN GURU DAN KEPALA SEKOLAH DALAM PENYUSUNAN KURIKULUM TINGKAT SATUAN PENDIDIKAN (KTSP) MELALUI PENDEKATAN "REMASEN"
}

\author{
Suparyana \\ Pengawas Madya Dinas Dikpora Daerah Istimewa Yogyakarta \\ Jl. Cendana 9 Yogyakarta Telp. (0274) 549142 Faksimile (0274) 513132
}

\begin{abstract}
ABSTRAK
Tujuan dari Pembinaan penyusunan KTSP melalui pendekatan "REMASEN" ini adalah tersusunnya Kurikulum Tingkat Satuan Pendidikan (KTSP) yang dapat dijadikan sebagai pedoman penyelenggaraan pendidikan di satuan pendidikan.

Metode pembinaan penyusunan KTSP melalui pendekatan religious, matematika, dan seni yang disingkat "REMASEN" . Pendekatan religious terdiri dari lima aspek, yaitu religious belief (aspek keyakinan), religious practice (aspek peribadatan), religious felling (aspek penghayatan), religious knowledge (aspek pengetahuan), dan religiuos effect (aspek pengamalan). Pendekatan matematika terdiri dari tiga aspek, yaitu berpikir kritis, sistematis, dan logis. Pendekatan seni terdiri dari tiga aspek, yaitu aspek nilai keindahan, nilai pengetahuan, dan nilai kehidupan.

Hasil yang dicapai adalah satuan pendidikan dapat menyusun KTSP sesuai dengan kondisi nyata, kondisi ideal, potensi, dan karakteristik yang dimiliki, sehingga visi yang disepakati dapat dijadikan sebagai cita-cita bersama warga satuan pendidikan dan segenap pihak yang berkepentingan pada masa yang akan datang, misi dapat memberikan arah dalam mewujudkan visi sesuai dengan tujuan pendidikan nasional, tujuan satuan pendidikan merupakan gambaran tingkat kualitas yang perlu dicapai dalam jangka menengah (empat tahunan).
\end{abstract}

Kata Kunci : Pembinaan, Religius, Matematika, Seni

\begin{abstract}
The purpose of coaching the making of SBC through the "REMASEN" approach is the compilation of Education Unit Level Curriculum (KTSP) which can be used as guidance of education in education unit.

The method of coaching the preparation of SBC through a religious, mathematical, and art approach abbreviated as "REMASEN". The religious approach consists of five aspects, namely religious belief (religious aspect), religious practice (religious aspect), religious logging (knowledge aspect), religious knowledge, and religious effect (aspect of practice). Mathematical approach consists of three aspects, namely critical thinking, systematic, and logical. The art approach consists of three aspects, namely the aspect of the value of beauty, the value of knowledge, and the value of life.

The results achieved are educational units that can flow KTSP in accordance with real conditions, ideal conditions, potentials, and characteristics possessed, Purpose that can be used as units together with the unit of education and all interested parties in the future, the mission can provide direction in realizing the vision in accordance with the objectives of national education, the purpose of the educational unit is one of the factors that need to be improved in the medium term (four years).
\end{abstract}

Keywords: Guidance, Religious, Mathematics, Art 


\section{Pendahuluan}

Hakikat Kurikulum Tingkat Satuan Pendidikan (KTSP) adalah sebagai pedoman penyelenggaraan pendidikan. Kurikulum merupakan acuan dalam menyelenggarakan pendidikan sekaligus sebagai tolok ukur pencapaian tujuan pendidikan. Berkaitan dengan hal tersebut maka setiap satuan pendidikan wajib menyusun Kurikulum Tingkat Satuan Pendidikan (KTSP). Setelah Kurikulum Tingkat Satuan Pendidikan (KTSP) tersusun kemudian dimintakan validasi ke pengawas pembina. Berdasarkan hasil validasi, ditemukan beberapa satuan pendidikan dalam menyusun Kurikulum Tingkat Satuan Pendidikan (KTSP) belum melalui analisis konteks, sehingga tidak mencerminkan kondisi nyata, kondisi ideal, potensi serta karakteristik satuan pendidikan tersebut.

Kondisi yang lebih memprihatinkan lagi adalah Kurikulum Tingkat Satuan Pendidikan (KTSP) hanya memfotocopy secara utuh dari sekolah lain yang kondisi nyata dan potensi, serta karakteristiknya berbeda. Permasalahan yang muncul adalah visi yang ada dalam Kurikulum Tingkat Satuan Pendidikan (KTSP) tersebut bukan merupakan citacita bersama warga satuan pendidikan, sekaligus misi yang ada tidak mencerminkan arah untuk mewujudkan visi, dampaknya tujuan pendidikan tidak menggambarkan kualitas yang perlu dicapai dalam jangka menengah. Apabila permasalahan ini tidak segera diselesaikan, maka Kurikulum Tingkat Satuan Pendidikan (KTSP) yang disusun tidak dapat dijadikan sebagai pedoman dalam pengelolaan satuan pendidikan tersebut.

Berdasarkan dua temuan di atas, yakni menyusun Kurikulum Tingkat Satuan Pendidikan (KTSP) tidak melaksanakan analisis konteks terlebih dahulu, memfotocopy sekolah yang lain tanpa penyesuaian, rumusan masalah yang dapat diajukan adalah apakah Kurikulum Tingkat Satuan Pendidikan (KTSP) seperti tersebut di atas dapat dijadikan sebagai pedoman dalam pengelolaan satuan pendidikan?

Berkaitan dengan rumusan masalah di atas, kami mengajukan alternative solusi yaitu pendekatan pembinaan melalui Trilogi pendekatan melalui Religious, Matematika, dan Seni (REMASEN).

a. Pendekatan melalui Religius

Pendekatan melalui dimensi religius terdiri dari lima aspek, yaitu

1) religious belief (aspek keyakinan),

2) religious practice (aspek peribadatan),

3) religious felling (aspek penghayatan), 
4) religious knowledge (aspek pengetahuan), dan

5) religiuos effect (aspek pengamalan). Glok dan Strak dalam Lies Arifah (2009: 12)

Sedangkan keyakinan di dalam hati dibentuk dengan 4 Pilar Keyakinan

1. Yakin yang diikuti dengan semangat

2. Yakin yang diikuti dengan kekuatan fokus.

3. Yakin yang diikuti dengan kedamaian pikiran.

4. Yakin yang diikuti dengan kebijaksanaan.

Keyakinan diri merupakan modal utama agar dapat mengambil semua keputusan tanpa keraguan sedikitpun, sehingga memiliki keberanian untuk mengambil tantangan baru dan menjalani hidup tanpa rasa takut.

Peribadatan merupakan pelaksanaan keputusan yang sudah tidak diragukan tentang kebenarannya.

Penghayatan merupakan roh dari peribadatan yang memberikan manusia mampu untuk mengetahui, menimbang, dan mengerti.

Pengetahuan merupakan dasar untuk melaksanakan keyakinan sehingga bernilai ibadah.

Pengamalan merupakan inti aspek religious, yakni empat aspek religious di atas tidak bermakna sama sekali apabila tidak diamalkan, dan sebaliknya suatu pengamalan tanpa didasari ilmu pengetahuan tidak bernilai. Dengan kata lain, ilmu harus diamalkan, amal harus dengan ilmu.

Lima aspek di atas senada dengan hakekat iman, yaitu iman harus diyakini dalam hati, diucapkan dengan lisan dan diamalkan dengan anggota badan. Dengan demikian, diharapkan pembinaan yang dilakukan oleh pengawas dapat meningkatkan keimanan guru maupun kepala sekolah.

b. Pendekatan melalui Matematika Menurut Johnson dan Rising dalam Russefendi (1972), bahwa matematika adalah pola berpikir, pola mengorganisasikan, pembuktian yang logis, dan suatu seni, keindahannya terdapat pada keterurutan dan keharmonisannya.

Menurut Kline

(1973), matematika itu bukan pengetahuan menyendiri yang dapat sempurna karena dirinya sendiri, tetapi adanya matematika itu terutama untuk membantu manusia dalam memahami dan menguasai permasalahan sosial, ekonomi, dan alam.

Kemampuan berpikir matematis akan mudah dibangun jika kita memberikan penekanan pada sifat dan 
prinsip matematika, misalnya pola dan hubungan

Dengan demikian pembinaan melalui pendekatan matematika diharapkan dapat membentuk pola pikir matematis, sehingga orang yang mempelajarinya akan terbiasa berpikir kritis, sistimatis dan logis.

Berpikir kritis adalah kemampuan untuk menganalisis fakta yang ada kemudian membuat beberapa gagasan dan mempertahankan gagasan tersebut kemudian membuat perbandingan. Dari beberapa perbandingan dapat diambil kesimpulan dan membuat solusi dari masalah yang ada. (Canche : 1986). Sistematis adalah berurutan, runtun,dan tidak tumpang tindih. (Abdulkadir Muhammad :2014).

Berpikir logis adalah sesuatu yang bisa diterima oleh akal dan yang sesuai dengan logika atau benar menurut penalaran. Berpikir secara logis adalah suatu proses berpikir dengan menggunakan logika, rasional dan masuk akal.

c. Pendekatan melalui Seni

Seni adalah keindahan dan seni adalah tujuan yang positif menjadikan penikmat merasa dalam kebahagiaan

(Alexander Baum Garton).

Seni adalah sebuah impian karena rumus rumus tidak dapat mengihtiarkan kenyataan.
(Immanuel Kant).

Seni merupakan hasil keindahan sehingga dapat menggerakkan perasaan indah orang yang melihatnya, oleh karena itu perbuatan manusia yang dapat mempengaruhi dapat menimbulkan perasaan indah itu seni.

(Ki Hajar Dewantara).

Pengertian Seni Musik adalah ungkapan perasaan seseorang yang dituangkan dalam bentuk nada dan syair yang indah

Berdasarkan pendapat di atas, seni dapat diartikan dengan sesuatu yang diciptakan manusia yang mengandung unsur keindahan.

The Liang Gie berpendapat bahwa jenis nilai yang melekat pada seni mencakup: 1) nilai keindahan, 2) nilai pengetahuan, 3) nilai kehidupan.

Nilai keindahan mempunyai pengertian, bisa menggerakkan perasaan indah orang lain yang menikmatinya sehingga merasa bahagia.

Nilai pengetahuan mempunyai pengertian, seseorang yang menikmati seni akan memperoleh kesan-kesan dari apa yang mereka dengar atau lihat. Kesan tersebut akan menjadi pengalaman dan pengetahuan baru.

Nilai kehidupan mempunyai pengertian, seseorang yang menikmati seni akan terpengaruh dengan karakter 
tokoh yang menjadi idolanya sehingga akan meniru.

Seorang menciptakan karya seni dengan tujuan meningkatkan kualitas kehidupan zamannya sehingga memilki arti penting bagi generasi berikutnya

Seni menurut media yang digunakan terbagi 3 yaitu :

a. Seni yang dapat dinikmati melalui media pendengaran atau (audio art), misalnya seni musik,seni suara, dan seni sastra seperti puisi dan pantun

b. Seni yang dinikmati dengan media penglihatan (Visual art)) misalnya lukisan, poster,seni bangunan, seni gerak beladiri dan sebagainya.

c. Seni yang dinikmati melalui media penglihatan dan pendengaran (audio visual art) misalnya pertunjukan musik, pagelaran wayang, film.

Pembinaan dilakukan secara umum dalam suatu pertemuan rutin dengan langkah-langkah sebagai berikut :

a. Meyakinkan guru dan atau kepala sekolah dengan nilai-nilai religious.

b. Mengajak guru dan atau kepala sekolah untuk berpikir matematis ( kritis, sistematis, logis). c. Mengajak guru dan atau kepala sekolah untuk menikmati penyajian seni, agar memperoleh nilai keindahan, nilai pengetahuan, dan nilai kehidupan.

Contoh pembinaan melalui pendekatan seni. Syair yang asli berjudul "Kucari Jalan Yang Terbaik" digubah menjadi "Sekolah Yang Maju dan Prestasi".

\section{SEKOLAH MAJU DAN PRESTASI}

Sepanjang kita masih belajar

Tak kan pernah tutup pintu prestasi

Perjuangan antara kita bersama

Sesungguhnya modal utama kita

Senyum dan sapa itu budaya kita

Semangat bekerja tuk meraih cita-cita

Berawal dari pahitnya perjuangan

Sekolah kita maju dan prestasi

$$
\text { Reff: }
$$

Kuingin ujudkan visi misi sekolahku

Walau gunung terjal pasti akan kudaki

Melangkah dan selalu melangkah

Pantang menyerah

Agar sekolahku maju dan prestasi

Makna dari syair di atas antara lain,

1. Allah tidak akan merubah nasib seseorang apabila orang tersebut tidak mau merubah nasibnya sendiri. 
2. Awal perjuangan memang pahit, namun hasilnya terasa manis.

3. Kurikulum Tingkat Satuan

Pendidikan yang didalamnya

termuat visi satuan pendidikan

jangan hanya sebagai slogan,

tetapi harus berusaha

mewujudkannya meskipun berat.

Tabel 1 Bentuk Pendekatan Pembinaan

\begin{tabular}{|c|c|c|c|}
\hline $\begin{array}{l}\text { Pendekatan } \\
\text { Pembinaan }\end{array}$ & & Aspek Pembinaan & Hasil yang Diharapkan \\
\hline \multirow[t]{5}{*}{ 1. Religius } & a. & $\begin{array}{l}\text { religious belief (aspek } \\
\text { keyakinan), }\end{array}$ & $\begin{array}{l}\text { yakin yang diikuti semangat, kekuatan focus, kedamaian } \\
\text { pikiran, dan kebijaksanaan }\end{array}$ \\
\hline & $b$. & $\begin{array}{l}\text { religious practice } \\
\text { (aspek peribadatan), }\end{array}$ & ibadah yang dilandasi keikhlasan dan kontinu \\
\hline & $c$. & $\begin{array}{l}\text { religious felling (aspek } \\
\text { penghayatan), }\end{array}$ & penghayatan yang diikuti dengan kesungguhan \\
\hline & d. & $\begin{array}{l}\text { religious knowledge } \\
\text { (aspek pengetahuan), }\end{array}$ & pengetahuan yang benar dan aktual \\
\hline & e. & $\begin{array}{l}\text { religiuos effect (aspek } \\
\text { pengamalan). }\end{array}$ & $\begin{array}{l}\text { pengamalan bukan sekedar menjalankan kewajiban } \\
\text { melainkan sudah menjadi kebutuhan }\end{array}$ \\
\hline \multirow[t]{3}{*}{$\begin{array}{l}\text { 2. Matemati } \\
\text { ka }\end{array}$} & a. & Berpikir Kritis & $\begin{array}{l}\text { mampu menganalisis fakta untuk dijadikan suatu } \\
\text { kesimpulan }\end{array}$ \\
\hline & b. & Berpikir Sistematis & berurutan, runtun, dan tidak tumpang tindih. \\
\hline & c. & Berpikir Logis & $\begin{array}{l}\text { berpikir dengan menggunakan logika, rasional dan masuk } \\
\text { akal }\end{array}$ \\
\hline \multirow[t]{3}{*}{ 3. Seni } & a. & Nilai Keindahan & rasa senang, puas, dan bangga \\
\hline & b. & Nilai Pengetahuan & pendidikan dan pembelajaran \\
\hline & c. & Nilai Kehidupan & kritik social dan hiburan \\
\hline
\end{tabular}


Tabel.2 Paradigma Lama Menuju Paradigma Baru

\begin{tabular}{|c|c|}
\hline $\begin{array}{l}\text { Paradigma Sebelum Pembinaan } \\
\text { Pendekatan "REMASEN" }\end{array}$ & $\begin{array}{l}\text { Paradigma Sesudah Pembinaan } \\
\text { Pendekatan "REMASEN" }\end{array}$ \\
\hline $\begin{array}{l}\text { 1. Kurikulum Tingkat Satuan Pendidikan } \\
\text { disusun tidak melalui analisis konteks } \\
\text { terlebih dahulu }\end{array}$ & $\begin{array}{l}\text { Kurikulum Tingkat Satuan Pendidikan disusun } \\
\text { melalui analisis konteks terlebih dahulu }\end{array}$ \\
\hline $\begin{array}{l}\text { 2. Kurikulum Tingkat Satuan Pendidikan } \\
\text { merupakan hasil foto copy dari sekolah lain }\end{array}$ & $\begin{array}{l}\text { Kurikulum Tingkat Satuan Pendidikan disusun } \\
\text { dengan berdasarkan kondisi nyata, kondisi } \\
\text { ideal, potensi, dan karakteristik sekolah. }\end{array}$ \\
\hline $\begin{array}{l}\text { 3. Visi, Misi, dan Tujuan yang berada dalam } \\
\text { kurikulum tingkat satuan pendidikan bukan } \\
\text { merupakan cita-cita bersama, dan tidak } \\
\text { menggambarkan kualitas yang dicapai } \\
\text { dalam jangka menengah sekolah }\end{array}$ & $\begin{array}{l}\text { 3. Visi, Misi, dan Tujuan yang berada dalam } \\
\text { kurikulum tingkat satuan pendidikan } \\
\text { merupakan cita-cita bersama, dan } \\
\text { menggambarkan kualitas yang dicapai dalam } \\
\text { jangka menengah sekolah }\end{array}$ \\
\hline Visi hanya dijadikan sebagai slogan sekolah & $\begin{array}{l}\text { 4. Visi dijadikan sebagai cita-cita bersama yang } \\
\text { diwujudkan di masa yang akan datang oleh } \\
\text { warga sekolah }\end{array}$ \\
\hline $\begin{array}{l}\text { 5. Kurikulum Tingkat Satuan Pendidikan } \\
\text { dijadikan sebagai pelengkap administrasi } \\
\text { sekolah }\end{array}$ & $\begin{array}{l}\text { 5. Kurikulum Tingkat Satuan Pendidikan } \\
\text { dijadikan sebagai pedoman penyelenggaraan } \\
\text { sekolah }\end{array}$ \\
\hline
\end{tabular}

\section{Kesimpulan}

Dari uraian di atas diperoleh kesimpulan sebagai berikut :

1. Dengan pendekatan religious tim penyusun kurikulum menyadari bahwa kebaikan akan kembali ke dirinya, maka Kurikulum Tingkat Satuan

2. Pendidikan (KTSP) disusun secara optimal agar menghasilkan kurikulum yang dapat dijadikan sebagai pedoman penyelenggaraan pendidikan di sekolahnya.

3. Dengan pendekatan matematika tim penyusun kurikulum berpikir kritis, sistematis, dan logis, yakni berusaha secara optimal penyusunan Kurikulum Tingkat Satuan Pendidikan (KTSP) sesuai prosedur, berurutan dan tidak tumpang tindih.

4. Dengan pendekatan seni tim penyusun kurikulum berusaha menampung masukan-masukan dari Pembinaan... (Suparyana) 
berbagai pihak yang terkait sehingga pelaksana Kurikulum Tingkat Satuan Pendidikan (KTSP) menjalankan dengan senang.

\section{Pustaka}

Abdulloh Munir. (2010). Pendidikan Karakter: Membangun Karakter Anak Sejak dari Rumah. Yogyakarta: Pedagogia.

Agus Wibowo. (2012). Pendidikan Karakter: Strategi Membangun KarakterBangsa Berkepribadian. Yogyakarta: Pustaka Pelajar.

Andi Hakim, N. (1980). Landasan Matematika, Jakarta : Bharata Aksara.

Erman, S dan Winataputra, U.S. (1993).

Strategi Belajar Mengajar Matematika, Jakarta : Universitas Terbuka.

Herman, H. (1990). Strategi Belajar Matematika, Malang : IKIP Malang.

Kemendiknas, (2011). Pedoman

\section{Pelaksanaan} Pendidikan Karakter. Jakarta: Kemendiknas Muhammad Riyadi, Fungsi musik dalam kehidupan manusia, https://muhamadriyadi333.word press.com/tentang-musik/fungsimusik-dalam-kehidupanmanusia/
Oleh Fendik Hariadi pada 8 Mei 2011 pukul 5:18, Bagaimana cara memandang keindahan sebuah karya seni?

Ruseffendi, E.T. (1988). Pengantar Kepada Membantu Guru Mengembangkan

Kompetensinya dalam Pengajaran Matematika Untuk Meningkatkan CBSA, Bandung : Tarsito.

Seni - Wikipedia bahasa Indonesia, ensiklopedia bebas

Zamroni. 2011. Pendidikan Demokrasi pada Masyarakat Multikultural. Yogyakarta: Gavin Kalam Utama 